\title{
Cerebral ischemic post-conditioning induces autophagy inhibition and a HMGB1 secretion attenuation feedback loop to protect against ischemia reperfusion injury in an oxygen glucose deprivation cellular model
}

\author{
JUE WANG, DONG HAN, MIAO SUN and JUAN FENG
}

\author{
Department of Neurology, Shengjing Hospital, \\ Affiliated Hospital of China Medical University, Shenyang, Liaoning 110004, P.R. China
}

Received October 15, 2015; Accepted August 5, 2016

DOI: $10.3892 / \mathrm{mmr} .2016 .5747$

\begin{abstract}
Cerebral ischemic postconditioning (IPOC) has been demonstrated to be neuroprotective against cerebral ischemia reperfusion injury. The present study aimed to determine whether IPOC could inhibit autophagy and high mobility group box 1 (HMGB1) release in a PC12 cell oxygen glucose deprivation/reperfusion (OGD/R) model. An $8 \mathrm{~h}$ OGD and $24 \mathrm{~h}$ reperfusion cellular model was developed to mimic cerebral ischemia reperfusion injury, with 3 cycles of $10 \mathrm{~min}$ OGD/5 min reperfusion treatment to imitate IPOC. Cell viability was determined to demonstrate the efficiency of OGD/R, IPOC and autophagy activator, rapamycin (RAP), treatment. Transmission electron microscopy was performed to observe the formation of autophagosomes, and immunofluorescence, western blot and co-immunoprecipitation were used to examine the expression of autophagy-associated proteins and HMGB1. Enzyme-linked immunosorbent assay analysis was conducted to examine the level of HMGB1 in cell supernatants. Additionally, PC12 cells were treated with RAP to examine the effect of autophagy on HMGB1 release, and the effect of recombinant human HMGB1 and Beclin1 small interfering RNA on autophagy was investigated. The present study confirmed that IPOC inhibited autophagy and HMGB1 secretion, autophagy inhibition induced a decrease in HMGB1 secretion, and HMGB1 secretion attenuation caused autophagy inhibition in return, as demonstrated by immunofluorescence and western blot analyses. Autophagy inhibition and HMGB1 secretion attenuation were, therefore, demonstrated to form a feedback loop under IPOC. These mechanisms illustrated the
\end{abstract}

Correspondence to: Dr Juan Feng, Department of Neurology, Shengjing Hospital, Affiliated Hospital of China Medical University, 36 Sanhao Street, Shenyang, Liaoning 110004, P.R. China E-mail: fengjuan99999@hotmail.com

Key words: PC12 cell, oxygen glucose deprivation/reperfusion, cerebral ischemic postconditioning, autophagy, high mobility group box 1 protective effects of IPOC and may accelerate the clinical use of IPOC.

\section{Introduction}

Stroke is a sudden onset cerebral circulation disorder, and is currently the second most common cause of mortality worldwide and the leading cause of disability in cerebrovascular patients (1). Since ischemic stroke is the most common type of stroke (1), the development of effective therapies remains a medical priority. Numerous treatments currently exist for ischemic stroke, primarily pharmacological and mechanical therapies, including cerebral ischemic postconditioning (IPOC). IPOC refers to the treatment of cerebral ischemia reperfusion (I/R) injury by several circulations of short term ischemia and reperfusion processes, which are induced before or several min after reperfusion (2). IPOC has been demonstrated to be an effective treatment in multiple cerebral ischemia models, such as focal and global cerebral ischemia reperfusion injury models $(3,4)$ with a high clinical value, since it can be used after the onset of ischemia and it exerts protective effects during different stages of ischemic stroke (2). Previous studies have revealed that IPOC can inhibit programmed cell death, including necrosis and apoptosis, to decrease infarct volume and improve neurological deficit (5).

Neuronal apoptosis following cerebral I/R injury can lead to the delayed neuronal cell death $(6,7)$. Autophagy is a conserved process in eukaryotic cells, which is closely associated with apoptosis; similarly to apoptosis, autophagy can lead to programmed cell death (8). Cerebral I/R can activate autophagy, and since autophagy activation is involved in the process of neuronal death, the treatment of cerebral I/R should target not only apoptosis, but also autophagy $(9,10)$. IPOC can inhibit autophagy induced by cerebral ischemia (11). Since reperfusion injury is a major component of stroke damage and the role of autophagy during I/R may be different, the present study initially aimed to elucidate whether IPOC can regulate autophagy during cerebral I/R. It has been reported that the combination of light chain 3 (LC3), Beclin1, and sequestome 1 (also known as P62) is representative of autophagy flux (12-14), 
therefore these parameters were employed to monitor the autophagy process.

High mobility group box 1 (HMGB1) is a transcription factor expressed in the majority of eukaryotic cells, including neurons (15). Under stress, it translocates to the cytoplasm and then to the extracellular matrix (16), where it induces inflammation by interacting with receptors to activate downstream signaling pathways (17). Increased plasma HMGB1 levels have been observed in patients with stroke (18) and in a mouse model of middle cerebral artery occlusion (19), and multiple treatment methods have been demonstrated to be effective in the treatment of cerebral I/R by decreasing the translocation and secretion of HMGB1, including drug treatments and hypoxic therapy $(20,21)$. HMGB1 is associated with autophagy $(22,23)$. Nuclear HMGB1 is involved in the regulation of membrane equilibrium during autophagy and mitophagy through upregulating the level of heat shock protein $\beta$ (24). When translocated to the cytoplasm, HMGB1 combines with the autophagy-associated protein Beclin1 to induce autophagy (25), whereas extracellular HMGB1 activates autophagy by interaction with the advanced glycosylation end product-specific receptor (26). However, it remains unclear whether IPOC regulates the translocation of HMGB1, or whether IPOC can induce autophagy through regulation of HMGB1.

The present study hypothesized that cerebral I/R injury activates autophagy by increasing HMGB1 and Beclin1 in a cellular modal of cerebral I/R, using oxygen and glucose deprivation and reperfusion $(\mathrm{OGD} / \mathrm{R})$ to mimic $\mathrm{I} / \mathrm{R}$, and that IPOC would inhibit autophagy and HMGB1 translocation.

\section{Materials and methods}

PC12 cell culture, OGD/R and IPOC treatment. PC12 cells (American Type Culture Collection, Manassas, VA, USA) were cultured with normal culture solution, formed by high glucose Dulbecco's modified Eagle's medium (DMEM, Gibco; Thermo Fisher Scientific, Inc., Waltham, MA, USA) supplemented with $10 \%$ fetal bovine serum (Gibco; Thermo Fisher Scientific, Inc., Waltham, MA, USA) and 7.5\% horse serum (Gibco; Thermo Fisher Scientific, Inc.). Cells were incubated in a humidified incubator at $37^{\circ} \mathrm{C}$ and $5 \% \mathrm{CO}_{2}$. For the induction of PC12 cells to neuronal PC12 cells, $10 \mathrm{nM} 7 \mathrm{~S}$ nerve growth factor (Sigma-Aldrich, St. Louis, MO, USA) was added to the culture medium following 3 days of cultivation.

Oxygen and glucose deprivation (OGD) experiments were performed using PC12 cells. Oxygen deprivation was induced by incubation of the culture dishes in a hypoxic chamber with $95 \% \mathrm{~N}_{2} / 5 \% \mathrm{CO}_{2}$ at $37^{\circ} \mathrm{C}$ for 2,4 and $8 \mathrm{~h}$. The glucose deprivation was introduced by exposing the cells to an ischemia-mimetic solution $(140 \mathrm{mmol} / 1 \mathrm{NaCl}, 3.5 \mathrm{mmol} / \mathrm{K} \mathrm{KCl}$, $0.43 \mathrm{mmol} / 1 \mathrm{KH}_{2} \mathrm{PO}_{4}, 1.25 \mathrm{mmol} / 1 \mathrm{MgSO}_{4}, 1.7 \mathrm{mmol} / 1 \mathrm{CaCl}_{2}$, $5 \mathrm{mmol} / \mathrm{l} \mathrm{NaHCO}, 20 \mathrm{mmol} / \mathrm{l} \mathrm{HEPES}, \mathrm{pH}$ 7.2-7.4). The buffer was exposed to $95 \% \mathrm{~N}_{2} / 5 \% \mathrm{CO}_{2}$ for $30 \mathrm{~min}$ before addition to the cells. The culture buffer changed to normal culture solution following OGD and incubated for $24 \mathrm{~h}$ to imitate the process of reperfusion. IPOC was performed by subjecting the cells to $1-3$ cycles of $10 \mathrm{~min}$ OGD/5 min reperfusion at $8 \mathrm{~h}$ following OGD, and then cultured with normal culture solution for $24 \mathrm{~h}$. The cells of normal control group were cultured in normal culture solution for the same period as the experimental groups. Intralipid solution (10\%; Sigma-Aldrich) at a concentration of $50 \mu \mathrm{M}$ was used as a vehicle control, it was used 10 min prior to and during OGD. Rapamycin (RAP; $100 \mathrm{nM}$ ), a specific mTOR inhibitor, was used as an autophagy activator. Recombinant human HMGB1 (RhHMGB1) was purchased from R\&D Systems China, Co., Ltd., (Shanghai, China; cat. no. p09429), which was diluted to a final concentration of $0.5 \mu \mathrm{g} / \mathrm{ml}$ prior to the onset of IPOC.

Cell viability analysis. PC12 cell viability was determined using a Cell Counting Kit-8 (CCK-8) cell viability assay (Dojindo Molecular Technologies, Inc., Kumamoto, Japan). PC12 cells were incubated in 96 well plates with 10,000 cells per well for cell viability analysis. Following the final $24 \mathrm{~h}$ incubation step of OGD/R or IPOC treatments, $20 \mu \mathrm{l} \mathrm{CCK-8}$ solution was added to each well containing $200 \mu \mathrm{l}$ culture medium. After incubating the cells at $37^{\circ} \mathrm{C}$ for $2 \mathrm{~h}$, the absorbance at $450 \mathrm{~nm}\left(\mathrm{~A}_{450}\right)$ was measured using a Multiskan FC microplate spectrophotometer (Thermo Fisher Scientific, Inc.). Cell viability (\%) was calculated as: $\left(\mathrm{A}_{450}\right.$ of test well / $\mathrm{A}_{450}$ of control well) x 100 .

Transfection of cells with Beclinl small interfering RNA (siRNA). PC12 cells were transiently transfected with siRNA against Beclin1 (Shanghai GenePharma Co., Ltd., Shanghai, China) or non-targeting control siRNA sequences (cat. no. B01001; Shanghai GenePharma Co., Ltd.) using Lipofectamine 2000 (Invitrogen; Thermo Fisher Scientific, Inc.) transfection reagent. The Beclin1 siRNA sequence was as follows: 5'-CCACCGUAAUUCACUUAGATTUCU AAGUGAAUUACGGUGGTT-3'. Cells were cultured in $60-\mathrm{mm}$ plates at a density of $4 \times 10^{5}$ cells per plate. Following $24 \mathrm{~h}$ normal cultivation, the culture medium was replaced with $1.8 \mathrm{ml}$ normal culture solution mixed with $200 \mu 1$ siRNA/Lipofectamine 2000 complex (containing $10 \mu \mathrm{l}$ siRNA, $10 \mu \mathrm{l}$ Lipofectamine 2000 and $180 \mu \mathrm{l}$ high glucose DMEM solution), and cells were incubated in the humidified incubator for $24 \mathrm{~h}$. Transfection efficiency was evaluated by western blot.

Transmission electron microscopic (TEM) observation of autophagosomes in PC12 cells. The PC12 cells for TEM observation were cultured in 60-mm plates. Following OGD/R and IPOC treatment, cells were fixed with $2 \%$ glutaraldehyde in $0.1 \mathrm{~mol} / 1$ phosphate-buffered saline (PBS) for 1 week at $4^{\circ} \mathrm{C}$. The cells were post-fixed in $1 \%$ osmium tetroxide in PBS at room temperature for $1 \mathrm{~h}$. Following dehydration, the cells were embedded in Epon 812, then sectioned with an ultramicrotome to produce sections $<100 \mathrm{~nm}$ in thickness, and stained with uranyl acetate and lead citrate at room temperature for $15 \mathrm{~min}$. Finally, the sections were observed using a JEM-1200EX transmission electron microscope (JEOL, Ltd., Tokyo, Japan). The number of autophagosomes was determined by counting manually, whereby 5 different fields of view per section were visualized and 3 sections for each group were analyzed.

Immunofluorescence detection. Immunofluorescence was used to evaluate the distribution and expression of Beclin1, HMGB1, microtubule associated-protein 1A/1B-LC3II and P62 in samples of PC12 cells from normal, OGD/R and IPOC 
groups. Cells $\left(\sim 3 \times 10^{5}\right)$ were cultivated in $60-\mathrm{mm}$ plates and were observed by confocal fluorescence microscopy for $24 \mathrm{~h}$ prior to treatment. Following 3 washes in PBS, cells were fixed with $4 \%$ paraformaldehyde at room temperature for $30 \mathrm{~min}$. Plates were then washed with PBS and blocked with 5\% bovine serum albumin (Gibco; Thermo Fisher Scientific, Inc.) at $37^{\circ} \mathrm{C}$ for $40 \mathrm{~min}$. For staining of LC3, Beclin1, P62 and HMGB1, the cells of the 3 groups were incubated with antibodies against LC3 (1:800; cat. no. NB600-1384; Novus Biologicals, LLC, Littleton, CO, USA), Beclin1 (1:100; cat. no. ab55878; RRID: AB_879596; Abcam), P62 (1:100; cat. no. ab91526; RRID: AB_2050336; Abcam) or HMGB1 (1:100; cat. no. ab79823; RRID: AB_1603373; Abcam) in a humidified container at $4{ }^{\circ} \mathrm{C}$ for $12 \mathrm{~h}$. Plates were washed 3 times in PBS, then incubated with tetramethylrhodamine-conjugated anti-rabbit IgG secondary antibody (1:100; cat. no. SA00009-1; Wuhan Sanying Biotechnology, Wuhan, China) at room temperature for $4 \mathrm{~h}$. To stain cell nuclei, plates were washed with PBS 3 times, then incubated with $0.0001 \%$ 4,6-diamidino-2-phenylindole (DAPI; Sigma-Aldrich) for $10 \mathrm{~min}$. Finally, plates were viewed using a Digital-Eclipse C1 laser confocal microscope (Nikon Corporation, Tokyo, Japan).

Enzyme-linked immunosorbent assay (ELISA) examination of cell supernatant HMGB1. Cells were cultured in $60 \mathrm{~mm}$ dishes for ELISA examination. Following OGD/R or IPOC treatment, cell supernatants were collected and centrifuged at $155 \mathrm{x} \mathrm{g}$ at $4^{\circ} \mathrm{C}$ for $5 \mathrm{~min}$ to remove the suspended cells. The concentration of HMGB1 in the supernatant was then determined using a commercial HMGB1 ELISA kit (cat. no. 326054329, Shino-Test Co., Tokyo, Japan) according to the manufacturer's protocol.

Co-immunoprecipitation and western blot analysis. PC12 cells were cultured in $100-\mathrm{mm}$ plates with $3 \times 10^{6}$ cells per plate, and then collected from the plates following treatments. Total protein was extracted from the cells using a commercially available kit (cat. no. KGP250; Nanjing KeyGen Biotech Co. Ltd., Nanjing, China). Cytosolic proteins were extracted using a Nuclear and Cytoplasmic Extraction kit (Beyotime Institute of Biotechnology, Jiangsu, China). For co-immunoprecipitation, HMGB1 antibody (1:1,000; cat. no. ab79823; Abcam) was added to the lysates and rotated overnight at $4^{\circ} \mathrm{C}$, then $20 \mu \mathrm{l}$ protein A agarose beads (for HMGB1 precipitation) were added for $3 \mathrm{~h}$. Co-immunoprecipitates were washed 3 times with $1 \mathrm{X}$ cell lysis buffer, consisting of radioimmunoprecipitation assay buffer (80\%), phosphatase inhibitor (10\%) and protease inhibitor (10\%). The supernatant was also collected as the unbound fraction and Beclin1 antibody (1:1,000; cat. no. ab55878; Abcam) was added to the solution and rotated overnight at $4^{\circ} \mathrm{C}$. A total of $20 \mu \mathrm{l}$ protein $\mathrm{A}$ agarose beads (for Beclin1 precipitation) was then added to the solution and incubated at $4^{\circ} \mathrm{C}$ for $3 \mathrm{~h}$. Co-immunoprecipitates were washed 3 times with $1 \mathrm{X}$ cell lysis buffer.

Whole cell lysates and immunoprecipitated proteins were boiled in sample buffer, separated by $10-15 \%$ sodium dodecyl sulfate-polyacrylamide gel electrophoresis, and transferred to a polyvinylidene fluoride membrane. Membranes were blocked with 5\% nonfat milk in Tris-buffered saline $+0.1 \%$ Tween-20 for $1 \mathrm{~h}$ at room temperature, then incubated overnight at $4^{\circ} \mathrm{C}$ with anti-LC3 (1:500; cat. no. ab62721; Abcam), anti-Beclin1 (1:1,000; cat. no. ab55878; Abcam), anti-P62 (1:1,000; cat. no. ab91526; Abcam), anti-HMGB1 (1:1,000; cat. no. ab79823; Abcam) and glyceraldehyde 3-phosphate dehydrogenase (GAPDH; 1:2,000; cat.no.sc365062; Santa CruzBiotechnology, Inc., Dallas, TX, USA), followed by an incubation with goat anti-rabbit IgG antibody (1:3,000; cat. no. SA00002-2; Wuhan Sanying Biotechnology). Immunoreactive bands were visualized using an enhanced chemiluminescence kit (Santa Cruz Biotechnology, Inc.), and protein bands were scanned using Chemi Imager 5500 V2.03 software (ProteinSimple, San Jose, CA, USA). The integrated density value (IDV) for each band was calculated with a computer-aided image analysis system (Fluor Chem 2.0; ProteinSimple). The IDV of LC3II was normalized against the IDV of LC3I, while the other proteins were normalized against the IDV of GAPDH.

Statistical analysis. All data are expressed as the mean \pm standard deviation. Data were analyzed by one-way analysis of variance followed by the Bonferroni test for multiple comparisons. $\mathrm{P}<0.05$ was considered to indicate a statistically significant difference.

\section{Results}

IPOC inhibits autophagy in the PC12 cell OGD/R model. CCK- 8 cell viability assays demonstrated that 2 h OGD and 24 h reperfusion significantly decreased cell viability to $\sim 84 \%$ of the level of normal control cells ( $\mathrm{P}=0.017$; Fig. $1 \mathrm{~A}), 4 \mathrm{~h}$ OGD and $24 \mathrm{~h}$ reperfusion decreased cell viability to $\sim 71 \%$ of the level of normal control cells $(\mathrm{P}=0.028$; Fig. 1A), and $8 \mathrm{~h}$ OGD and $24 \mathrm{~h}$ reperfusion decreased cell viability to $\sim 51 \%$ of the level of normal control cells ( $\mathrm{P}=0.042$; Fig. 1A). However, IPOC was observed to increase cell viability

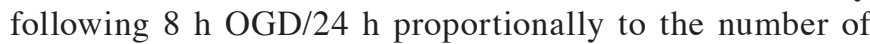
IPOC cycles that were performed (Fig. 1B): 1 cycle of $10 \mathrm{~min}$ IPOC (IPOC1) resulted in $64 \%$ of the viability of normal control cells, 2 cycles of $10 \mathrm{~min}$ IPOC (IPOC2) resulted in $71 \%$ of the viability of normal control cells, while 3 cycles of $10 \mathrm{~min}$ IPOC (IPOC3) resulted in $83 \%$ of the viability of normal control cells and a significant improvement in cell viability compared with 8 h OGD and $24 \mathrm{~h}$ reperfusion ( $\mathrm{P}=0.033$; Fig. 1B). Therefore, 3 cycles of $10 \mathrm{~min}$ OGD and 5 min reperfusion were used as the 'IPOC treatment' for the remainder of the study. Autophagosomes were examined by TEM. A small number of autophagosomes were observed in normal control group PC12 cells (Fig. 1C). Following OGD/R, cells revealed some double-membrane vacuoles containing engulfed cytoplasmic material, suggesting the formation of autophagosomes (Fig. 1D). However, in the IPOC group, the number of autophagosome was visibly reduced compared to the OGD/R group (Fig. 1E). Quantification of autophagosomes revealed a significantly higher number of autophagosomes in the OGD/R group compared with the normal control group $(\mathrm{P}=0.013$; Fig. $1 \mathrm{~F})$, and significantly fewer in the IPOC group compared with the OGD/R group $(\mathrm{P}=0.034$; Fig. $1 \mathrm{~F})$.

Immunofluorescence of autophagy-associated proteins LC3II, Beclin1 and P62 revealed that OGD/R upregulated levels of LC3II (Fig. 2A) and Beclin1 (Fig. 2B), and decreased levels of P62 (Fig. 2C) compared with the normal control 
A

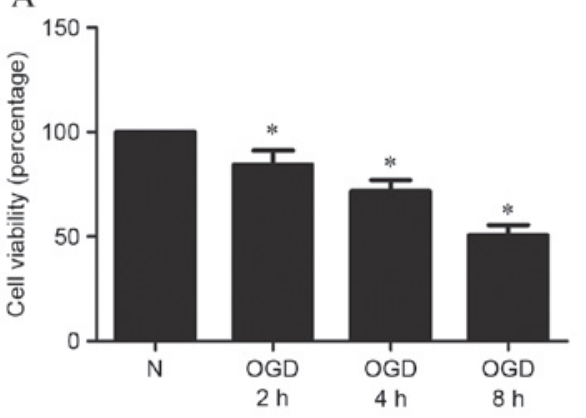

$\mathrm{C}$

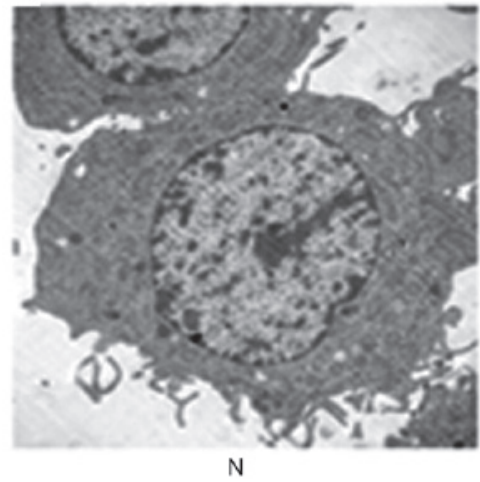

$\mathrm{E}$

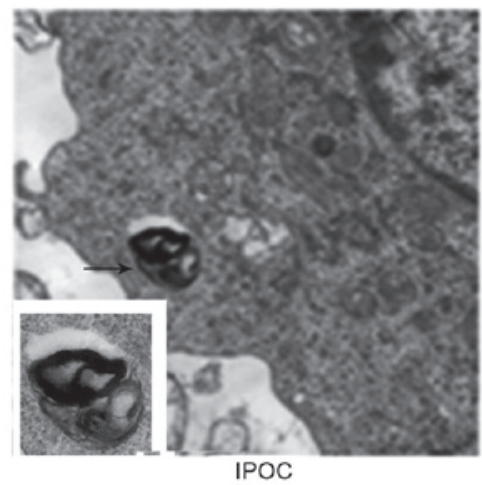

B

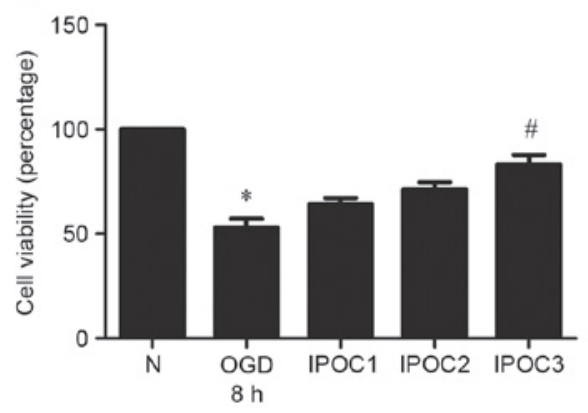

D

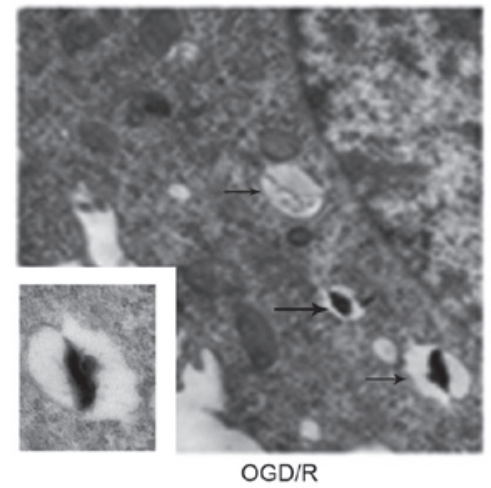

F

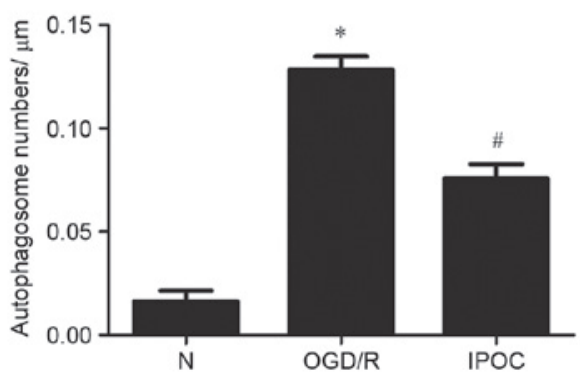

Figure 1. Cell viability and TEM results of cells following OGD or IPOC. (A) PC12 cell viability was evaluated by CCK-8 assay following treatments of 2 , 4 and $8 \mathrm{~h}$ OGD prior to reperfusion; (B) PC12 cell viability was evaluated by CCK-8 following $8 \mathrm{~h}$ OGD, followed by $0,1,2$ or 3 cycles of IPOC; (C) TEM scanning of normal control group PC12 cells (magnification, x3,000); (D) TEM scanning of the OGD/R group ( $8 \mathrm{~h}$ OGD followed by $24 \mathrm{~h}$ reperfusion; magnification, x3,000); (E) TEM scanning of the IPOC group (OGD/R plus 3 cycles of IPOC; magnification, x3,000); (F) statistical analysis of autophagosomal number following TEM. Data are presented as the mean \pm standard deviation of 3 samples per group. ${ }^{~} \mathrm{P}<0.05$ vs. normal control group, ${ }^{~} \mathrm{P}<0.05 \mathrm{vs}$. OGD/R group. TEM, transmission electron microscopy; CCK-8, cell counting Kit-8; N, normal control; OGD/R, oxygen and glucose deprivation and reperfusion; IPOC, ischemic post-conditioning.

group. IPOC abolished the OGD-mediated activation of autophagy, which was demonstrated by the decreased expression of LC3II and Beclin1 and increased expression of P62. Immunofluorescence of $\mathrm{HMGB} 1$ revealed that $\mathrm{OGD} / \mathrm{R}$ resulted in translocation of HMGB1, which is usually located in the nucleus, to the cytoplasm (Fig. 2D). However, this translocation was also revealed to be inhibited by IPOC (Fig. 2D).

Western blot analysis was also used to assess the change in expression levels of the LC3II, Beclin1 and P62 proteins (Fig. 3A). Similarly to immunofluorescence, western blotting revealed that, compared with the normal control group, OGD/R upregulated the levels of LC3II ( $\mathrm{P}=0.024$; Fig. 3B), Beclin1 $(\mathrm{P}<0.05$; Fig. 3C) and decreased levels of P62 $(\mathrm{P}=0.035$; Fig. 3D). IPOC had the opposite effect, resulting in reduced levels of LC3II ( $\mathrm{P}=0.028$; Fig. 3B), Beclin1 ( $\mathrm{P}=0.032$; Fig. 3C) and increased levels of $\mathrm{P} 62(\mathrm{P}=0.044$; Fig. 3D) compared with OGD/R treatment. Quantitative western blot analysis also revealed that levels of cytoplasmic HMGB1 were increased by OGD/R compared with the normal control group $(\mathrm{P}=0.031$; Fig. 3E), and decreased by IPOC compared with $\mathrm{OGD} / \mathrm{R}$ $(\mathrm{P}=0.018$; Fig. 3E). In addition, ELISA was used to evaluate altered HMGB1 levels in the cell supernatant; the level of extracellular HMGB1 was significantly higher in the OGD/R group compared with the normal control group $(\mathrm{P}=0.037$; Fig. 3F), but this effect was attenuated by IPOC $(\mathrm{P}=0.029$ OGD/R vs. IPOC; Fig. 3F).

IPOC inhibits autophagy to reduce the secretion of HMGB1. An autophagy activator, RAP, was used prior to IPOC to examine the effect on autophagy inhibition. CCK-8 cell viability assays demonstrated that RAP significantly eliminated the protective effect of IPOC $(\mathrm{P}=0.023$, IPOC vs. IPOC + RAP; Fig. 4A), reducing cell viability to $54 \%$ of the normal control group. Western blot analysis demonstrated that the 
A
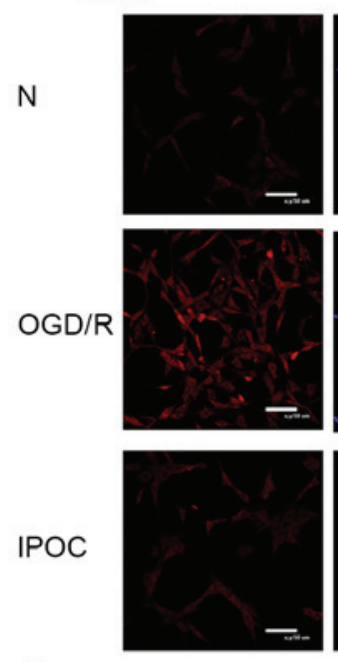

C

P62

N

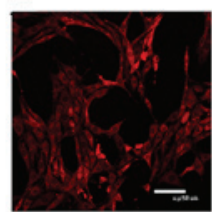

OGD/R

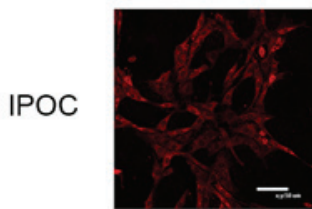

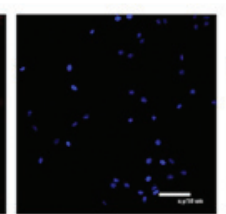
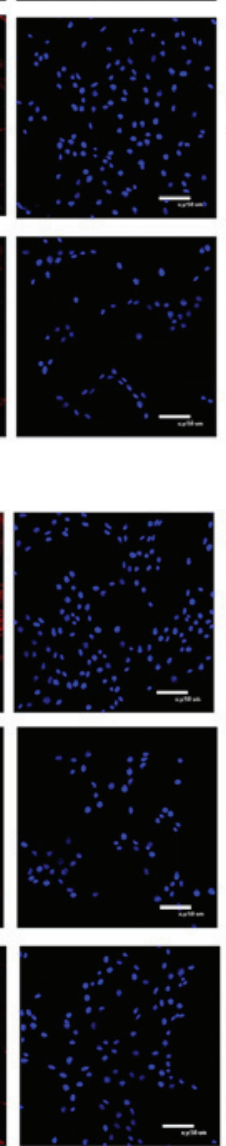

B
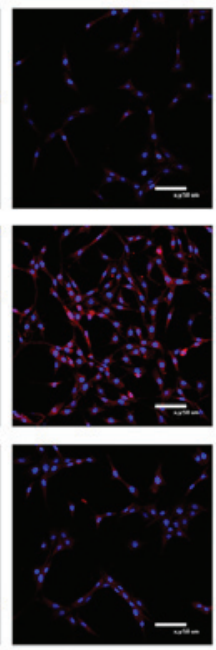

OGD/R

Beclin1

N
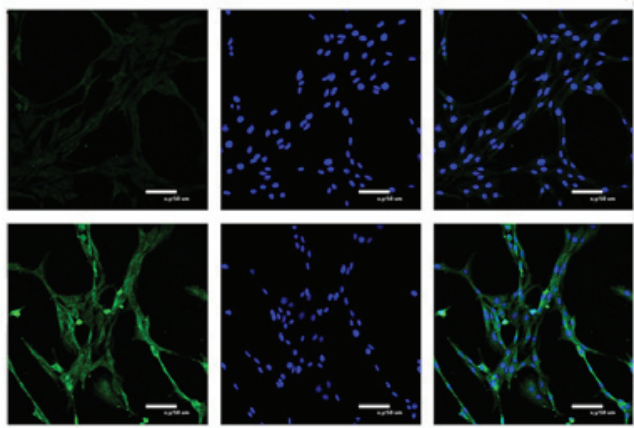

IPOC
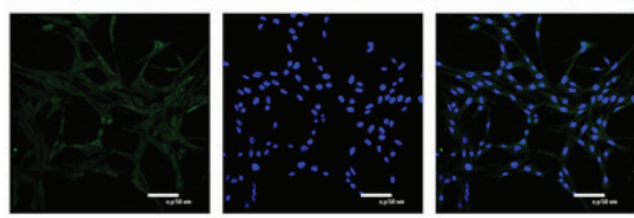

D ${ }_{\text {HMGB1 }}$

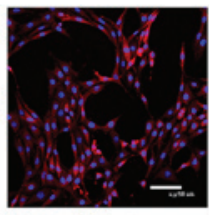

$\mathrm{N}$
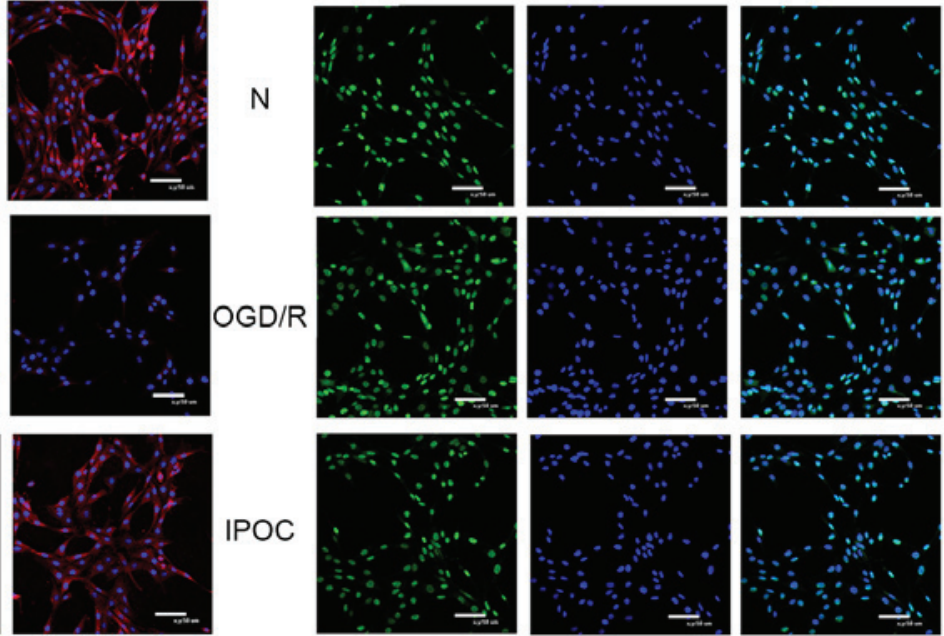

Figure 2. Immunofluorescence images of PC12 cells to detect markers of autophagy. (A) LC3II, (B) Beclin1, (C) P62, and (D) HMGB1 expression was demonstrated by immunofluorescence staining in cells from the N, OGD/R ( $8 \mathrm{~h}$ OGD followed by $24 \mathrm{~h}$ reperfusion) and IPOC (OGD/R plus 3 cycles of IPOC) groups. Scale bars represent $50 \mu \mathrm{m}$. The left column shows immunofluorescence staining of the specific markers, the middle column represents staining of the cell nuclei with DAPI, and the right column shows the left and middle images merged. N, normal control group; OGD/R, oxygen and glucose deprivation and reperfusion; IPOC, ischemic post-conditioning; LC3II, microtubule associated-protein 1A/1B-light chain 3 II; P62, sequestome 1; HMGB1, high mobility group box 1 .

reduction in LC3II and Beclin1 expression as a result of IPOC was significantly abolished by pre-treatment with RAP $(\mathrm{P}=0.032$ and $\mathrm{P}=0.041$, IPOC vs. IPOC + RAP; Fig. $4 \mathrm{C}$ and $\mathrm{D}$, respectively), while the reverse effect on $\mathrm{P} 62$ expression was observed ( $\mathrm{P}=0.021$, IPOC vs. IPOC + RAP; Fig. 4E). The quantitative analysis of cytoplasmic (Fig. 4F and G) and extracellular HMGB1 (Fig. 4H) revealed that expression and secretion of HMGB1 was reactivated by the use of RAP $(\mathrm{P}=0.017$ and $\mathrm{P}=0.037$, IPOC vs. IPOC + RAP; Fig. $4 \mathrm{G}$ and $\mathrm{H}$, respectively).

IPOC attenuates the interaction between Beclinl and HMGBI to in hibit autophagy. To examine whether OGD/R and IPOC affected the interaction between Beclin1 and HMGB1, co-immunoprecipitation was performed. Anti-HMGB1 antibody was used to immunoprecipitate the intracellular protein complex, revealing that $\mathrm{OGD} / \mathrm{R}$ increased the quantity of Beclin1 bound to HMGB1 compared with the normal control group ( $\mathrm{P}=0.022$; Fig $5 \mathrm{~A}$ and $\mathrm{B})$, while IPOC reversed this effect $(\mathrm{P}=0.012$, OGD/R vs. IPOC; Fig $5 \mathrm{~A}$ and $\mathrm{B})$. The effect on HMGB1 was same as that of Beclin1: OGD/R increased the quantity of HMGB1 detected compared with the normal control group ( $\mathrm{P}=0.042$; Fig $5 \mathrm{~A}$ and $\mathrm{C})$, while IPOC again reversed this effect $(\mathrm{P}=0.035$, OGD/R vs. IPOC; Fig 5A and C). The proportion of free Beclin1 isolated from the cell supernatant remained unchanged (Fig. 5A and D). These results indicate that OGD may increase the interaction of HMGB1 with Beclin1, whereas IPOC abolishes their interaction.

To further demonstrate the association between Beclin1 and HMGB1 interactions and autophagy activation, Beclin1 siRNA and rhHMGB1 were, respectively, used to inhibit the expression of Beclin1 and simulate overexpression of HMGB1. Expression levels of Beclin1 were significantly reduced following transfection with Beclin1 siRNA compared with the normal control group ( $\mathrm{P}=0.032$; Fig. 6A). Beclin1 expression 
A

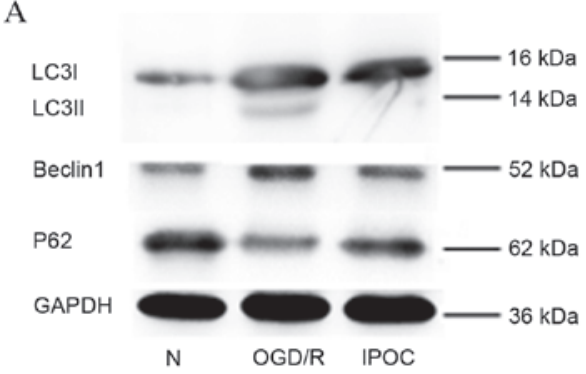

C

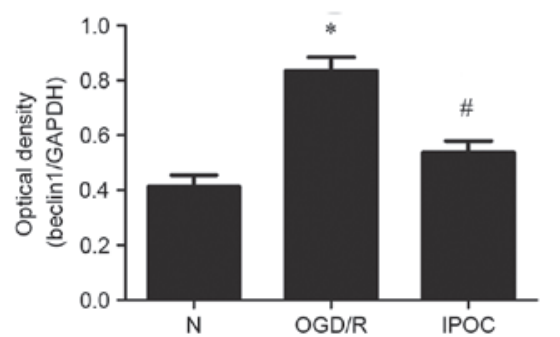

E

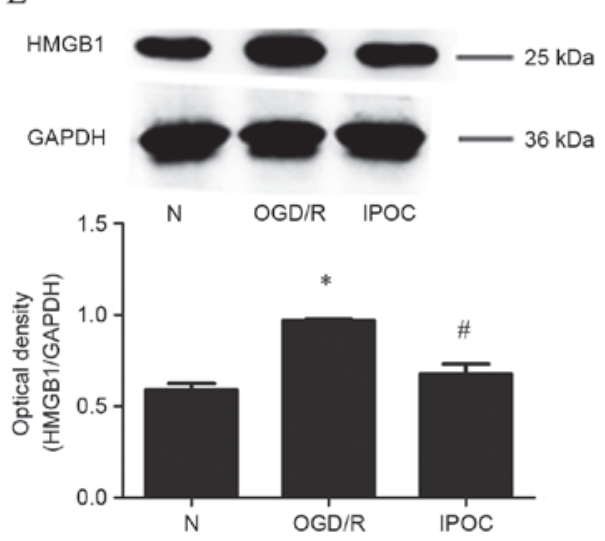

B

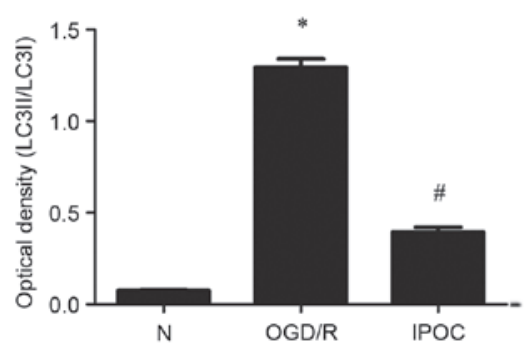

D

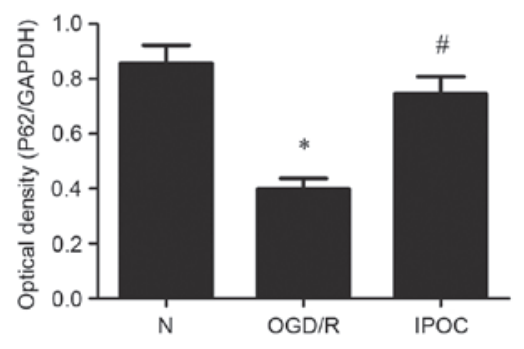

F

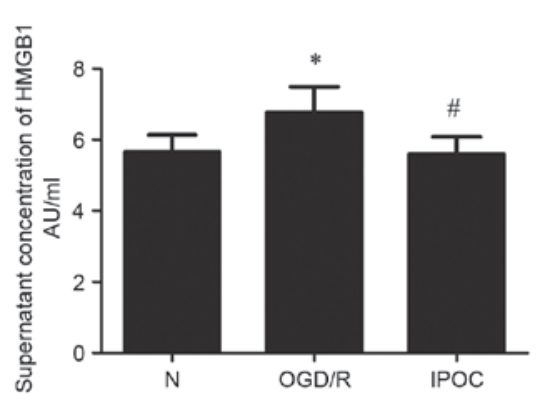

Figure 3. Analysis of protein expression levels of autophagy related proteins and HMGB1 following OGD/R ( $8 \mathrm{~h}$ OGD followed by $24 \mathrm{~h}$ reperfusion) and IPOC (OGD/R plus 3 cycles of IPOC). (A) Autophagy related proteins were detected by western blot; (B) quantitative analysis of LC3II protein relative to LC3I; (C) quantitative analysis of Beclin1 protein relative to GAPDH; (D) quantitative analysis of P62 protein relative to GAPDH; (E) cytoplasmic HMGB1 detected by western blot and quantitated relative to GAPDH; (F) quantitative analysis of cell supernatant HMGB1 protein detected by enzyme-linked immunosorbent assay. Data are presented as the mean \pm standard deviation of 3 samples per group. ${ }^{*} \mathrm{P}<0.05$ vs. normal control group, ${ }^{\prime} \mathrm{P}<0.05$ vs. OGD/R group. LC3, microtubule associated-protein 1A/1B-light chain 3; P62, sequestome 1; GAPDH, glyceraldehyde 3-phosphate dehydrogenase; HMGB1, high mobility group box 1; $\mathrm{N}$, normal control group; OGD/R, oxygen and glucose deprivation and reperfusion; IPOC, ischemic post-conditioning.

was similarly decreased in cells transfected with Beclin1 siRNA and treated with OGD/R compared with the OGD/R condition $(\mathrm{P}=0.031$; Fig. $6 \mathrm{~B})$. Compared with IPOC alone, the use of rhHMGB1 in addition to IPOC significantly increased the level of expression of LC3II ( $\mathrm{P}=0.021$; Fig. 6B and $\mathrm{C}$ ), Beclin1 ( $\mathrm{P}=0.024$; Fig. 6B and $\mathrm{D})$, attenuated $\mathrm{P} 62$ expression $(\mathrm{P}=0.033$; Fig. $6 \mathrm{~B}$ and $\mathrm{E})$ and increased the level of HMGB1 $(\mathrm{P}=0.012$; Fig. $6 \mathrm{~B}$ and $\mathrm{F})$. The simultaneous application of IPOC, Beclin1 siRNA and rhHMGB1 induced a similar effect to IPOC alone, resulting in significantly reduced levels of LC3II ( $\mathrm{P}=0.024$; Fig. 6B and $\mathrm{C})$, Beclin1 ( $\mathrm{P}=0.015$; Fig. 6C and $\mathrm{D})$, increased levels of $\mathrm{P} 62(\mathrm{P}=0.014$; Fig. $6 \mathrm{C}$ and $\mathrm{E})$ and decrease the expression of HMGB1 ( $\mathrm{P}=0.041$; Fig. $6 \mathrm{~B}$ and $\mathrm{F})$ compared with $\mathrm{OGD} / \mathrm{R}$ treatment. In conclusion, the results demonstrate that the autophagy inhibition effect of IPOC may be due to its role in decreasing interactions between HMGB1 and Beclin1.

\section{Discussion}

IPOC is an effective treatment for cerebral I/R injury, while autophagy has been considered as a target for the treatment of ischemic stroke (2). The elevation of plasma HMGB1 in cerebral ischemic model and patients with stroke is associated with worsened injury, and there is a close association between HMGB1 secretion and autophagy activation $(19,23)$. Thus, it will be important to examine the mutual interaction between HMGB1 secretion and autophagy activation following IPOC. The current study demonstrated that IPOC inhibits autophagy activation and HMGB1 release in the OGD/R model. Additionally, it was revealed that IPOC inhibited autophagy to reduce the translocation of HMGB1 from the nucleus to the cytoplasm, and the autophagy inhibition effect of IPOC may be caused by attenuation of the interaction between HMGB1 and Beclin1. 

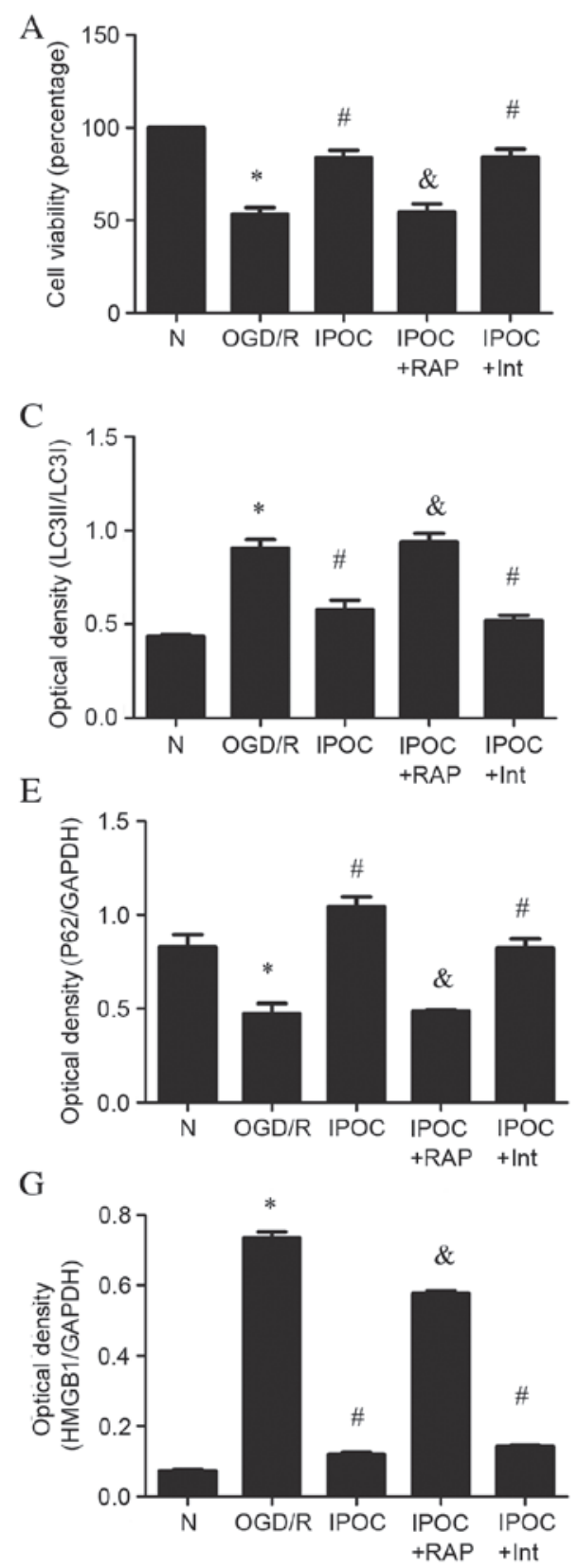

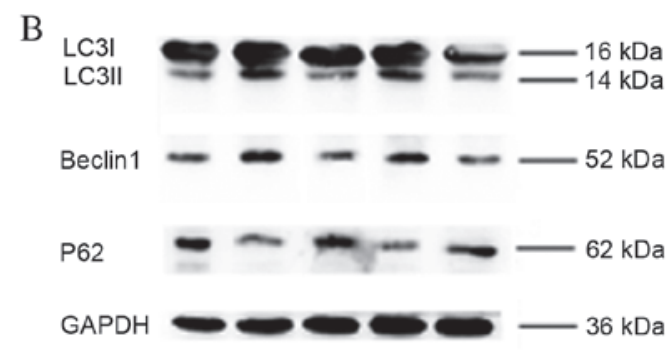

N OGD/R IPOC IPOC IPOC + RAP + Int

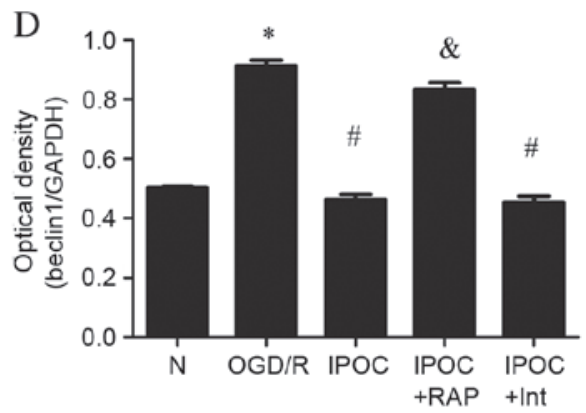

$\mathrm{F}$

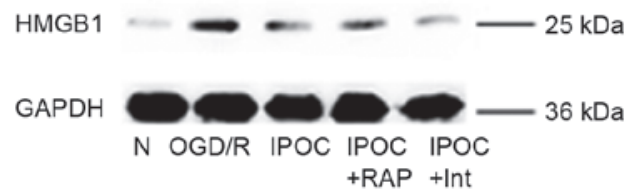

$\mathrm{H}$

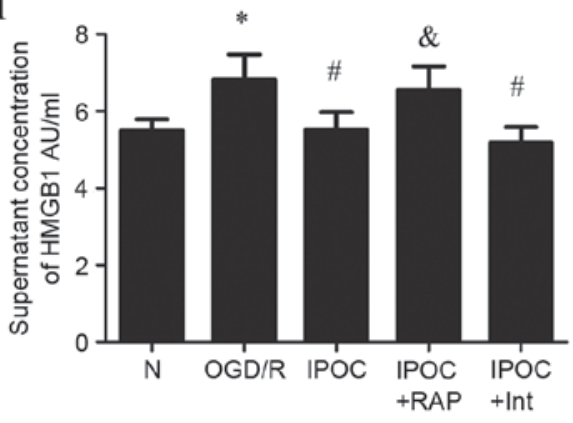

Figure 4. The effect of the autophagy activator, RAP, on IPOC (OGD/R plus 3 cycles of IPOC). (A) Cell viability evaluated using a CCK-8 assay; (B) expression levels of autophagy related proteins were detected by western blot; (C) quantitative analysis of LC3II protein relative to LC3I; (D) quantitative analysis of Beclin1 protein relative to GAPDH; (E) quantitative analysis of P62 protein relative to GAPDH; (F) cytoplasmic HMGB1 detected by western blot; (G) quantitative analysis of cytoplasmic HMGB1 protein relative to GAPDH; $(\mathrm{H})$ quantitative analysis of cell supernatant HMGB1 protein detected by enzyme-linked immunosorbent assay. Data are presented as the mean \pm standard deviation of 3 samples per group. ${ }^{*} \mathrm{P}<0.05$ vs. normal control group, ${ }^{\#} \mathrm{P}<0.05$ vs. OGD/R group, ${ }^{\&} \mathrm{P}<0.05$ vs. IPOC group. N, normal control group; OGD/R ( $8 \mathrm{~h}$ OGD followed by $24 \mathrm{~h}$ reperfusion), oxygen and glucose deprivation and reperfusion; IPOC, ischemic post-conditioning; RAP, rapamycin; Int, Intralipid vehicle control; LC3, microtubule associated-protein 1A/1B-light chain 3; P62, sequestome 1; GAPDH, glyceraldehyde 3-phosphate dehydrogenase; HMGB1, high mobility group box 1.

Cellular models are important in mechanistic studies, therefore, the present study developed and applied a novel and convenient PC12 cell model of OGD/R and IPOC, which may be useful in the future studies of IPOC. In the present study, PC12 cells were subjected to $8 \mathrm{~h}$ OGD plus $24 \mathrm{~h}$ reperfusion to mimic I/R, followed by 1-3 cycles of $10 \mathrm{~min}$ OGD and 5 min reperfusion to mimic IPOC in a cellular model. CCK-8 viability assays demonstrated that 3 cycles of IPOC (10 min OGD and 5 min reperfusion) had the most potent effect on cell viability in the OGD/R model, increasing cell viability from
51 to $83 \%$. This was, therefore, the IPOC model used for the remainder of the study.

Autophagy has been viewed as a double-edged sword during the process of cardiac I/R (27); autophagosomes are formed to encapsulate damaged organelles and other large molecular structures to promote the reuse of materials and energy (28), however, the formation of too many autophagosomes results in depletion of necessary substances for cell maintenance, resulting in the death of the cell (8). Autophagy is protective during the process of cardiac ischemia but 


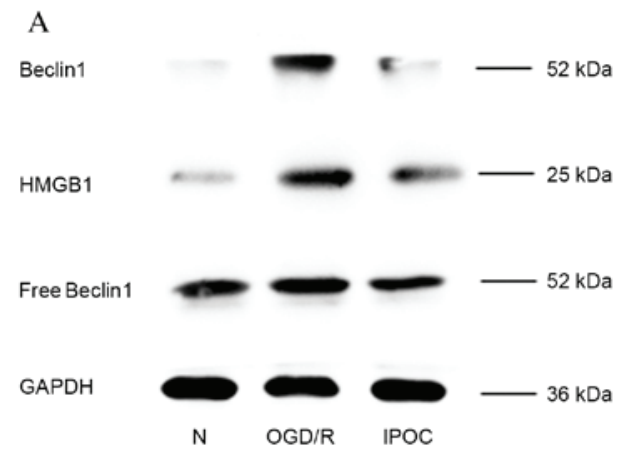

B

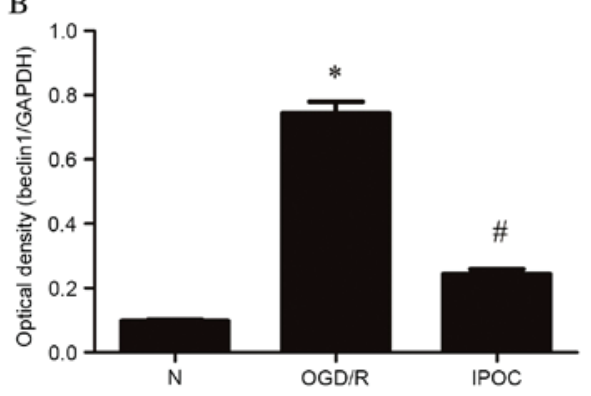

$\mathrm{C}$

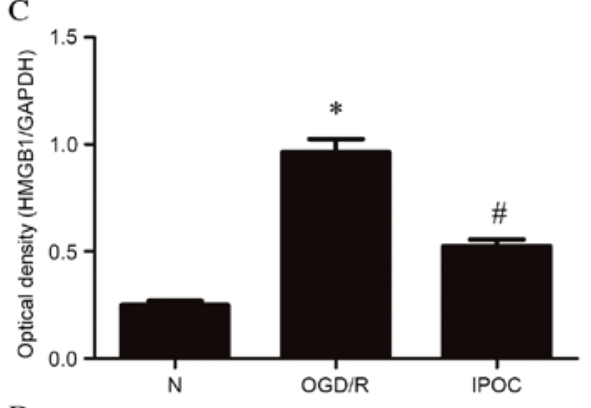

$\mathrm{D}$

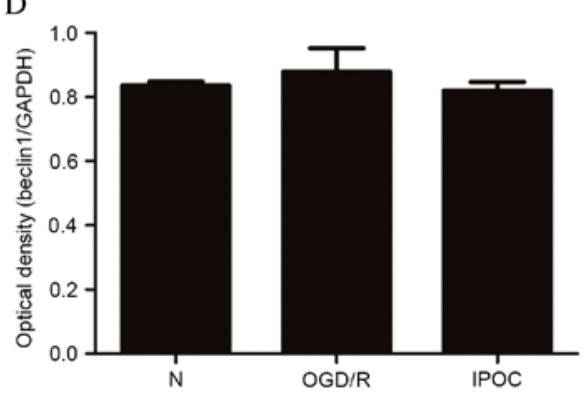

Figure 5. HMGB1 and Beclin1 co-immunoprecipitation. (A) Beclin1 and HMGB1 protein detected by western blot; (B) quantitative analysis of HMGB-bound Beclin1 relative to GAPDH; (C) quantitative analysis of HMGB1 protein relative to GAPDH; (D) quantitative analysis of free Beclin 1 relative to GAPDH. Data are presented as the mean \pm standard deviation of 3 samples per group. ${ }^{*} \mathrm{P}<0.05$ vs. normal control group, ${ }^{*} \mathrm{P}<0.05$ vs. OGD/R group. HMGB1, high mobility group box 1; GAPDH, glyceraldehyde 3-phosphate dehydrogenase; $\mathrm{N}$, normal control group; OGD/R (8 h OGD followed by $24 \mathrm{~h}$ reperfusion), oxygen and glucose deprivation and reperfusion; IPOC (OGD/R plus 3 cycles of IPOC), ischemic post-conditioning.

causes destruction during reperfusion (27). Its role in cerebral I/R injury has, thus far, not been fully elucidated. Numerous studies have demonstrated a protective role of autophagy $(29,30)$, while others have confirmed a destructive role in cerebral ischemia (31). Apoptosis has been considered as a key target for the treatment of cerebral I/R, since it is a form of programmed cell death, which is involved in the process of delayed neuronal death $(6,7)$. Recent studies have confirmed that, like apoptosis, autophagy can result in the death of neurons $(8,31)$. The processes of apoptosis and autophagy are linked; the anti-apoptotic protein B cell lymphoma 2 apoptosis regulator ( $\mathrm{Bcl}-2)$ is also involved in autophagic pathways (32). The autophagic marker Beclin1 possesses a Bcl-2-homology-3 (BH3)-only domain, which facilitates its binding with the $\mathrm{BH} 3$ binding groove of multi-domain proteins, thus, Bcl-2 interacts with Beclin1 to target Beclin1-dependent autophagic pathway (33). Numerous methods have been developed to target autophagy in the treatment of cerebral I/R injury $(10,34)$. IPOC can inhibit autophagy activation induced by cerebral ischemia (11), however, the involvement of IPOC in the process of autophagy in cerebral I/R has, thus far, not been thoroughly investigated. The present study demonstrated that the activation of autophagy reduced cell viability in an OGD/R cellular model of I/R, and that IPOC inhibited autophagy activation and HMGB1 release. In addition, the use of an autophagy activator, RAP, reversed the protective effect of IPOC. IPOC was also demonstrated to reduce the translocation of HMGB1 from the nucleus to the cytoplasm, and that the autophagy inhibition effect of IPOC may be caused by reduced interaction between HMGB1 and Beclin1. These results are consistent with the findings of our previous study (35), which confirmed that IPOC decreased the translocation of HMGB1 from the nucleus to the cytoplasm to exert its autophagy inhibition effect in an in vivo model of focal cerebral ischemia and IPOC. The current study adds further evidence for the mechanism of HMGB1-induced autophagy in ischemic stroke and IPOC.

Autophagy activation has been demonstrated to be induced by the secretion of HMGB1 (23), which interacts with the autophagy-associated protein, Beclin1, and displaces Bcl-2 (25). HMGB1 exerts different functions depending on its cellular locations. Nuclear HMGB1 is considered to be a non-histone nuclear DNA-binding protein, which helps to maintain the homeostasis of the nucleus and can facilitate the bending of DNA to regulate gene expression (36). However, extracellular HMGB1 acts as an inflammatory factor by binding with its receptor to stimulate downstream pathways (37). HMGB1 is released following ischemic stroke and is regarded as a marker of the severity of ischemic stroke in clinical studies (18). In a rat cerebral I/R model, plasma HMGB1 levels were rapidly elevated following injury $(38,39)$, while in clinical studies, elevated HMGB1 levels can be observed in patient serum for 7 days following subarachnoid hemorrhage (40). Methods have, therefore, been developed to decrease the level of plasma HMGB1 $(19,20)$. The present study revealed that IPOC inhibits the secretion of HMGB1, and confirmed this by demonstrating a decrease of cytoplasmic and extracellular HMGB1 in cells in the IPOC group compared with the OGD/R group. Furthermore, the decreased secretion of HMGB1 in the IPOC group was a result of autophagy inhibition, since the use of RAP reversed the downregulation of HMGB1 induced by IPOC. HMGB1 has been demonstrated to associate with Beclin1 to activate autophagy in the cytoplasm (25); the present study used co-immunoprecipitation to study the interaction between HMGB1 and Beclin1. While the level of combined Beclin1 
A

B
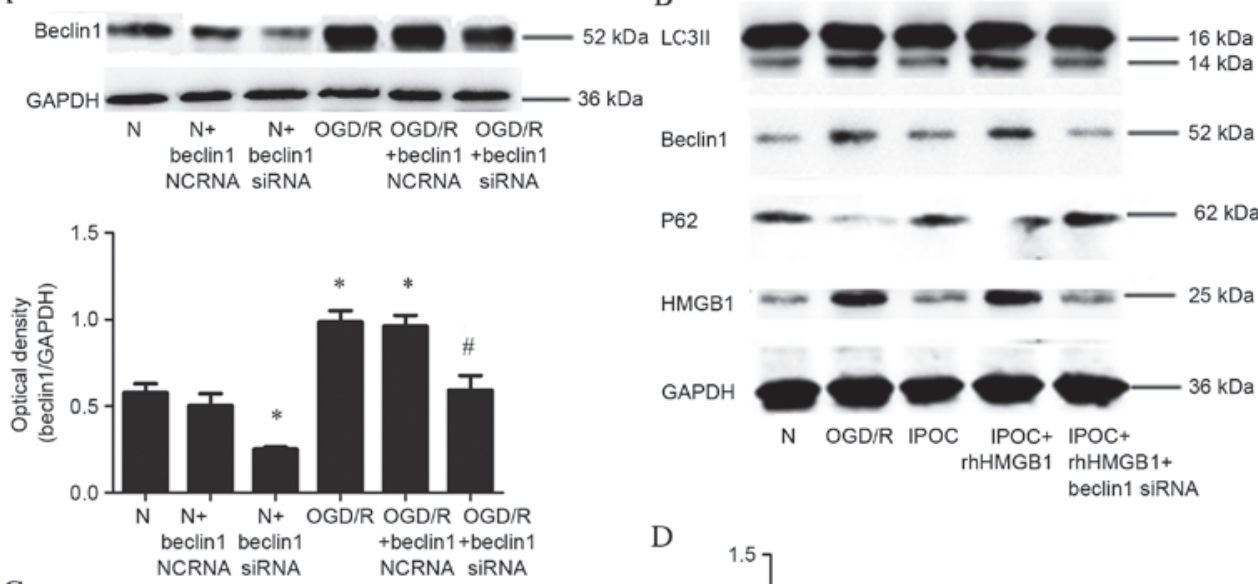

$N$ OGD/R IPOC IPOC+ IPOC+ rhHMGB1 rhHMGB1+ beclin1 siRNA

C

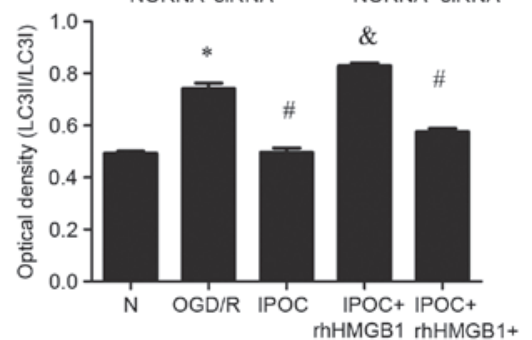

D

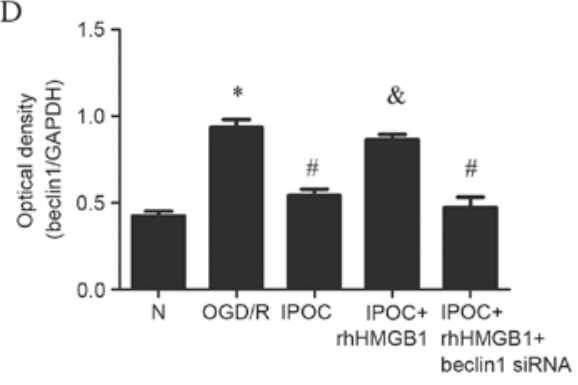

E
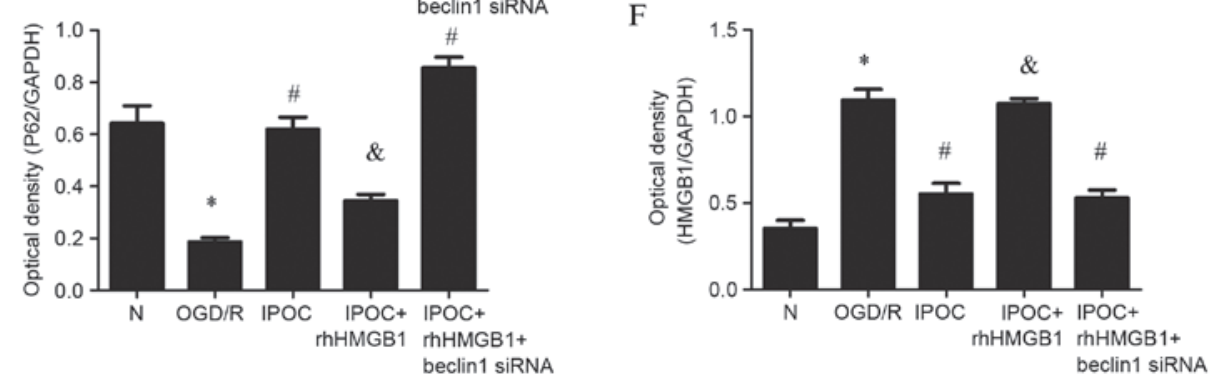

Figure 6. Effect of rhHMGB1 and Beclin1 siRNA. (A) Beclin1 protein levels detected by western blot following Beclin1 siRNA treatment in normal and OGD/R ( $8 \mathrm{~h}$ OGD followed by $24 \mathrm{~h}$ reperfusion) groups and quantitative analysis of Beclin1 was performed following Beclin1 siRNA treatment relative to GAPDH; (B) autophagy related proteins detected by western blot; (C) quantitative analysis of LC3II protein relative to LC3I; (D) quantitative analysis of Beclin1 protein relative to GAPDH; (E) quantitative analysis of P62 protein relative to GAPDH; (F) quantitative analysis of cytoplasmic HMGB1 protein relative to GAPDH. Data are presented as the mean \pm standard deviation of 3 samples per group. ${ }^{~} \mathrm{P}<0.05$ vs. normal control group, ${ }^{"} \mathrm{P}<0.05$ vs. OGD/R group, ${ }^{\&} \mathrm{P}<0.05$ vs. IPOC group. N, normal control group; NCRNA, negative control siRNA; siRNA, small interfering RNA; OGD/R, oxygen and glucose deprivation and reperfusion; LC3, microtubule associated-protein 1A/1B-light chain 3; P62, sequestome 1; HMGB1, recombinant human high mobility group box 1; GAPDH, glyceraldehyde 3-phosphate dehydrogenase; IPOC (OGD/R plus 3 cycles of IPOC), ischemic post-conditioning; rhHMGB1, recombinant human HMGB1.

and HMGB1 was low in normal cells, OGD/R increased the incidence of combined Beclin1 and HMGB1, while IPOC reversed this effect. However, as the HMGB1 levels were also increased by $\mathrm{OGD} / \mathrm{R}$ and decreased by IPOC it is unclear whether OGD/R and IPOC affected the level of interaction between the two proteins, or whether the level of expression of HMGB1 was altered without affecting its interaction with Beclin1. The levels of total Beclin1 protein and free Beclin1 in the supernatant were then assessed following HMGB1 immunoprecipitation in all treatment groups. The level of free Beclin1 was revealed to be unchanged between treatment groups, while the level of total Beclin1 was increased by OGD/R and decreased by IPOC. These results, therefore, indicated that the combination of HMGB1 and Beclin1 is increased by $\mathrm{OGD} / \mathrm{R}$ and decreased by IPOC. To further elucidate the association between HMGB1, Beclin1 combination and autophagy activation, recombinant human HMGB1 and Beclin1 siRNA were used prior to IPOC to upregulate
HMGB1 and decrease Beclin1, respectively. Overexpression of HMGB1 was revealed to reverse the autophagy inhibition effect of IPOC, but did not induce the activation of autophagy under the conditions of Beclin1 inhibition. Therefore, IPOC was demonstrated to attenuate the interaction between HMGB1 and Beclin1 to induce autophagy inhibition. HMGB1 inhibition may also result in other effects besides autophagy inhibition, which will be examined in future studies.

In conclusion, IPOC simultaneously inhibits autophagy and HMGB1 secretion, and mutual regulation exists between these two processes; autophagy inhibition leads to decreased HMGB1 secretion, while the inhibition of HMGB1 release causes the attenuation of cytoplasmic HMGB1, decreasing interactions between HMGB1 and Beclin1 to further inhibit the process of autophagy. Therefore, a positive feedback mechanism exists between IPOC inhibition of autophagy process and decreased HMGB1 secretion. The present study has further elucidated the mechanisms of IPOC in 
a cellular model of cerebral I/R injury. As a method, which simultaneously affects two key therapeutic targets of cerebral I/R injury (autophagy and HMGB1), IPOC has huge potential for clinical application.

\section{Acknowledgements}

This study was partially supported by a grant from the Liaoning Province Science and Technology Project-Animal Scientific Research and Clinical Application for Major Disease of Liaoning Province (grant no. 2012225021) and Science and Technology Projects of Liaoning Province (grant no. 2009225010-2) to Dr Feng.

\section{References}

1. Writing Group Members, Mozaffarian D, Benjamin EJ, Go AS, Arnett DK, Blaha MJ, Cushman M, Das SR, de Ferranti S, Després JP, et al: Executive summary: Heart disease and stroke statistics-2016 update: A report from the American heart association. Circulation 133: 447-454, 2016.

2. Zhao $\mathrm{H}$ : Ischemic postconditioning as a novel avenue to protect against brain injury after stroke. J Cereb Blood Flow Metab 29: 873-885, 2009

3. Duanmu WS, Cao L, Chen JY, Ge HF, Hu R and Feng H: Ischemic postconditioning protects against ischemic brain injury by up-regulation of acid-sensing ion channel 2a. Neural Regen Res 11: 641-645, 2016.

4. Han D, Zhang S, Fan B, Wen LL, Sun M, Zhang H and Feng J: Ischemic postconditioning protects the neurovascular unit after focal cerebral ischemia/reperfusion injury. J Mol Neurosci 53: 50-58, 2014.

5. Yuan Y, Guo Q, Ye Z, Pingping X, Wang N and Song Z: Ischemic postconditioning protects brain from ischemia/reperfusion injury by attenuating endoplasmic reticulum stress-induced apoptosis through PI3K-Akt pathway. Brain Res 1367: 85-93, 2011.

6. Zhu C, Xu F, Wang X, Shibata M, Uchiyama Y, Blomgren K and Hagberg H: Different apoptotic mechanisms are activated in male and female brains after neonatal hypoxia-ischaemia. J Neurochem 96: 1016-1027, 2006

7. Li J, Han B, Ma X and Qi S: The effects of propofol on hippocampal caspase-3 and $\mathrm{Bcl}-2$ expression following forebrain ischemia-reperfusion in rats. Brain Res 1356: 11-23, 2010.

8. Bowen ID, Mullarkey K and Margen SM: Programmed cell death during meta-morphosis in the blow-fly Calliphora vormitoria. Microsc Res Tech 34: 202-217, 1996.

9. Wen YD, Sheng R, Zhang LS, Han R, Zhang X, Zhang XD, Han F, Fukunaga K and Qin ZH: Neuronal injury in rat model of permanent focal cerebral ischemia is associated with activation of autophagic and lysosomal pathways. Autophagy 4: 762-769, 2008.

10. Koike M, Shibata M, Tadakoshi M, Gotoh K, Komatsu M, Waguri S, Kawahara N, Kuida K, Nagata S, Kominami E, et al: Inhibition of autophagy prevents hippocampal pyramidal neuron death after hypoxic-ischemic injury. Am J Pathol 172: 454-469, 2008.

11. Gao L, Jiang T, Guo J, Liu Y, Cui G, Gu L, Su L and Zhang Y: Inhibition of autophagy contributes to ischemic postconditioning-induced neuroprotection against focal cerebral ischemia in rats. PLoS One 7: e46092, 2012.

12. Chakrabarti L, Eng J, Ivanov N, Garden GA and La Spada AR: Autophagy activation and enhanced mitophagy characterize the Purkinje cells of ped mice prior to neuronal death. Mol Brain 2: 24, 2009 .

13. Erlich S, Shohami E and Pinkas-Kramarski R: Neurodegeneration induces upregulation of Beclin 1. Autophagy 2: 49-51, 2006.

14. Kabeya Y, Mizushima N, Ueno T, Yamamoto A, Kirisako T, Noda T, Kominami E, Ohsumi Y and Yoshimori T: LC3, a mammalian homologue of yeast Apg8p, is localized in autophagosome membranes after processing. EMBO J 19: 5720-5728, 2000.

15. Goodwin GH, Sanders C and Johns EW: A new group of chromatin associated proteins with a high content of acidic and basic amino acids. Eur J Biochem 38: 14-19, 1973.
16. Wang H, Bloom O, Zhang M, Vishnubhakat JM, Ombrellino M, Che J, Frazier A, Yang H, Ivanova S, Borovikova L, et al: HMGB-1 as a late mediator of endotoxin lethality in mice. Science 285: 248-251, 1999.

17. Yang QW, Wang JZ, Li JC, Zhou Y, Zhong Q, Lu FL and Xiang J: High-mobility group protein box-1 and its relevance to cerebral ischemia. J Cereb Blood Flow Metab 30: 243-254, 2010.

18. Huang JM, Hu J, Chen N and Hu ML: Relationship between plasma high-mobility group box-1 levels and clinical outcomes of ischemic stroke. J Crit Care 28: 792-797, 2013.

19. Rickenbacher A, Jang JH, Limani P, Ungethüm U, Lehmann K, Oberkofler CE, Weber A, Graf R, Humar B and Clavien PA: Fasting protects liver from ischemic injury through sirt1-mediated downregulation of circulating HMGB1 in mice. J Hepatol 61: 301-308, 2014

20. Nakamura T, Yamada S and Yoshioka T: Brain hypothermic therapy dramatically decreases elevated blood concentrations of high mobility group box 1 in neonates with hypoxic-ischemic encephalopathy. Dis Markers 35: 327-330, 2013.

21. Wang Q, Wang F, Li X, Yang Q, Li X, Xu N, Huang Y, Zhang Q, Gou X, Chen S and Xiong L: Electroacupuncture pretreatment attenuates cerebral ischemic injury through $\alpha 7$ nicotinic acetylcholine receptor-mediated inhibition of high-mobility group box 1 release in rats. J Neuroinflammation 9: 24, 2012.

22. Kang R, Zeh HJ, Lotze MT and Tang D: The Beclin 1 network regulates autophagy and apoptosis. Cell Death Differ 18: 571-580, 2011.

23. Thorburn J, Frankel AE and Thorburn A: Regulation of HMGB1 release by autophagy. Autophagy 5: 247-249, 2009.

24. Tang D, Kang R, Livesey KM, Kroemer G, Billiar TR, Van Houten B, Zeh HJ III and Lotze MT: High-mobility group box 1 is essential for mitochondrial quality control. Cell Metab 13: 701-711, 2011.

25. Tang D, Kang R, Livesey KM, Cheh CW, Farkas A, Loughran P, Hoppe G, Bianchi ME, Tracey KJ, Zeh HJ III and Lotze MT: Endogenous HMGB1 regulates autophagy. J Cell Biol 190: 881-892, 2010.

26. Tang D, Kang R, Cheh CW, Livesey KM, Liang X, Schapiro NE Benschop R, Sparvero LJ, Amoscato AA, Tracey KJ, et al: HMGB1 release and redox regulates autophagy and apoptosis in cancer cells. Oncogene 29: 5299-5310, 2010.

27. Juhaszova M, Zorov DB, Yaniv Y, Nuss HB, Wang S and Sollott SJ: Role of glycogen synthase kinase-3beta in cardioprotection. Circ Res 104: 1240-1252, 2009.

28. Cuervo AM: Autophagy: In sickness and in health. Trends Cell Biol 14: 70-77, 2004

29. Sheng R, Zhang LS, Han R, Liu XQ, Gao B and Qin ZH: Autophagy activation is associated with neuroprotection in a rat model of focal cerebral ischemic preconditioning. Autophagy 6 : 482-494, 2010.

30. Su J, Zhang T, Wang K, Zhu T and Li X: Autophagy activation contributes to the neuroprotection of remote ischemic perconditioning against focal cerebral ischemia in rats. Neurochem Res 39: 2068-2077, 2014.

31. Wang JY, Xia Q, Chu KT, Pan J, Sun LN, Zeng B, Zhu YJ, Wang Q, Wang K and Luo BY: Severe global cerebral ischemia-induced programmed necrosis of hippocampal CA1 neurons in rat is prevented by 3-methyladenine: A widely used inhibitor of autophagy. J Neuropathol Exp Neurol 70: 314-322, 2011.

32. Pattingre S, Tassa A, Qu XP, Garuti R, Liang XH, Mizushima N, Packer M, Schneider MD and Levine B: Bcl-2 antiapoptotic proteins inhibit Beclin 1-dependent autophagy. Cell 122: 927-939, 2005

33. Funderburk SF, Wang QJ and Yue Z: The Beclin 1-VPS34 complex-at the crossroads of autophagy and beyond. Trends Cell Biol 20: 355-362, 2010.

34. Cui D, Wang L, Qi A, Zhou Q, Zhang X and Jiang W: Propofol prevents autophagic cell death following oxygen and glucose deprivation in PC12 cells and cerebral ischemia-reperfusion injury in rats. PLoS One 7: e35324, 2012.

35. Wang J, Han D, Sun M and Feng J: A combination of remote ischemic perconditioning and cerebral ischemic postconditioning inhibits autophagy to attenuate plasma HMGB1 and induce neuroprotection against stroke in rat. J Mol Neurosci 58: 424-431, 2016.

36. Zhang CC, Krieg S and Shapiro DJ: HMG-1 stimulates estrogen response element binding by estrogen receptor from stably transfected HeLa cells. Mol Endocrinol 13: 632-643, 1999. 
37. Wang H, Bloom O, Zhang M, Vishnubhakat JM, Ombrellino M, Che J, Frazier A, Yang H, Ivanova S, Borovikova L, et al: HMG1 as a late mediator of endotoxin lethality in mice. Science 285: 248-251, 1999.

38. Hayakawa K, Mishima K, Nozako M, Hazekawa M, Mishima S Fujioka M, Orito K, Egashira N, Iwasaki K and Fujiwara M: Delayed treatment with minocycline ameliorates neurologic impairment through activated microglia expressing a high-mobility group box 1-inhibiting mechanism. Stroke 39: 951-958, 2008.
39. Qiu J, Nishimura M, Wang Y, Sims JR, Qiu S, Savitz SI, Salomone S and Moskowitz MA: Early release of HMGB-1 from neurons after the onset of brain ischemia. J Cereb Blood Flow Metab 28: 927-938, 2008.

40. Nakahara T, Tsuruta R, Kaneko T, Yamashita S, Fujita M, Kasaoka S, Hashiguchi T, Suzuki M, Maruyama I and Maekawa T: High-mobility group box 1 protein in CSF of patients with subarachnoid hemorrhage. Neurocrit Care 11: 362-368, 2009. 